\title{
THREE-DIMENSIONAL MODELLING OF A TWO-LAYER POROUS BURNER FOR HOUSEHOLD APPLICATIONS
}

\author{
T. Hayashi ${ }^{1}$, I. Malico ${ }^{2 *}$ and J. C. F. Pereira ${ }^{1}$ \\ ${ }^{1}$ Instituto Superior Técnico, Mechanical Engineering Department, Av. Rovisco Pais, 1049- \\ 001 Lisboa, Portugal \\ ${ }^{2}$ Universidade de Évora, Physics Department, Av. Romão Ramalho, 59, 7000-671 Évora, \\ Portugal, Fax: +351 266702 306, e-mail: imbm@uevora.pt
}

\section{Abstract}

A finite-volume calculation of the three-dimensional reacting flow in a porous burner is presented. The Navier-Stokes, energy and species transport equations are solved, and radiative heat transfer under local thermal non-equilibrium between the solid and gas phases is considered. Strong dissipation of the jets from the perforated plate is observed, contributing to the flame stabilization inside the ceramic foam. Simulation results for several operating conditions point to the potential for damage of the perforated plate, owing to the high radiative and conductive fluxes, and to the necessity of using smaller pore diameters to avoid flashback.

Keywords: Porous media, combustion, heat transfer, CFD, flame stabilization, burner design.

\footnotetext{
${ }^{*}$ Corresponding author
} 